\title{
The Drying of Foods and Its Effect on the Physical-Chemical, Sensorial and Nutritional Properties
}

\author{
Raquel P. F. Guiné \\ CI\&DETS/ESAV, Polytechnic Institute of Viseu/Department of Food Industry, Viseu, Portugal \\ CERNAS, Polytechnic Institute of Coimbra, Bencanta, Coimbra, Portugal \\ Email: raquelguine@esav.ipv.pt
}

\begin{abstract}
Drying of foods is an ancient practice that has been adopted to preserve foods beyond their natural shelf life. The process started with the exposure of foods to the sun, to extract from them a great proportion of the water, thus contributing for their conservation. The traditional solar dying with direct exposure to the sun had many disadvantages and presently more modern methods are used, such as hot air drying, spray drying, lyophilization, infrared, microwave or radiofrequency drying, osmotic dehydration or many combined processes. Many foods can be preserved through drying, but their organoleptic and nutritional properties are greatly altered as compared to the fresh counterparts. The objective of this paper is to describe the contents of a plenary speech presentation about the advances in drying methods and the effects of drying on the attributes of the dried foods. For that a search in the scientific literature was conducted and the selection of the information was based on the topics aimed at discussing.
\end{abstract}

Index Terms - drying methods, colour, texture, organoleptic properties, chemical composition, nutrition

\section{INTRODUCTION TO FOOD DRYING}

Among the numerous methods used for food conservation, drying is unquestionably the most ancient but still very much used nowadays. It is a process by which water is removed from the food, by vaporization or sublimation, thus reducing the water available for degradation reactions of chemical, enzymatic or microbial nature. The drying rate is influenced by transfer mechanisms, such as the vapour pressures of the food and of the drying air, temperature and air velocity, moisture diffusion in the product, thickness and surface exposed for drying [1].

Drying involves the use of heat to vaporize the water present in the food, and also the removal of the water vapour from the food surface. Hence, it combines heat and mass transfer for which energy must be supplied. To use hot air flowing over the food is the most common way of transferring heat to a drying material, being this process mainly by convection [2].

Manuscript received May 17, 2017; revised October 11, 2017.
The main objectives of drying include to preserve foods and increase their shelf life by reducing the water content and water activity; avoid the need for use of refrigeration systems for transport and storage (expensive); reduce space requirements for storage and transport; diversify the supply of foods with different flavours and textures, thus offering the consumers a great choice when buying foods [3], [4].

Although drying is an alternative to extend the shelf life of food and also facilitating storage and transportation, by reducing the need of expensive cooling systems, it is a fact that the quality of dehydrated food is usually drastically reduced as compared to that of the original foodstuff. Thus, it is of interest to minimize chemical changes, such as enzymatic and non-enzymatic browning, and to maximize nutrient retention, such as macronutrients (proteins, sugars, fibres, ...), micronutrients (vitamins, minerals, ...) or bioactive compounds (phenolic compounds, carotenoids, isoflavones, ...) during drying. One effect frequently observed when drying foods is shrinkage, which considerably affects their structure and texture [5].

\section{DRYING METHODS}

Water loss from foods is a very energy-intensive process. Drying involves a considerable energy consumption: $20-25 \%$ of the energy used by the food processing industry or $10-25 \%$ of the energy used in all industries in developed countries. Hence, energy together with time efficiency represents one of the most significant design and operation parameters in food processing [6]. Low thermal conductivity and casehardening of materials are the main factors responsible for slowing down the convective drying.

There have been many advances in drying technology in latest years, including pretreatments, techniques, equipment and quality of the final products. The pretreatments, for example, are used with the aim to accelerate the drying process, enhance quality and improve the safety of foodstuffs [7]. Besides they also help decreasing energy needs.

There are hundreds of types of dryers, based on different principles of operation, as shown in Table I. 
TABLE I. ClassiFiCATION OF DRIERS

\begin{tabular}{|c|c|}
\hline Discontinuous functioning & Continuous functioning \\
\hline $\begin{array}{l}\text { - Biggest hand labour costs. } \\
\text { - May have greater variations } \\
\text { product quality from batch to } \\
\text { batch. } \\
\text { - More economical for smaller } \\
\text { capacities (up to } 5 \text { tons/day). }\end{array}$ & $\begin{array}{l}\text { - More economical for large } \\
\text { quantities of material. }\end{array}$ \\
\hline Direct heating & Indirect heating \\
\hline $\begin{array}{l}\text { - The material is placed in } \\
\text { contact with the hot gases } \\
\text { that provide the latent heat } \\
\text { for vaporization of water. }\end{array}$ & $\begin{array}{l}\text { - The food is separated from } \\
\text { the heat source by a physical } \\
\text { barrier such as a metal } \\
\text { surface. }\end{array}$ \\
\hline
\end{tabular}

\section{A. Solar Drying}

In solar drying the energy source is the sun. Therefore it is a very cheap drying method, but on the other hand it has many drawbacks because the food is exposed to contamination sources (insects, birds and other animals) and is also strongly susceptible to weather conditions (Fig 1). Hence, the sanitary quality may be compromised and product losses can occur due to food spoilage when the conditions are not favourable, before reaching a stable moisture content. The solar greenhouses may minimize these problems because while keeping the sun as energy source, they are very efficient and reach higher temperatures due to the greenhouse effect, and besides the foods are protected [8], [9].

In the direct solar drying the product is exposed to solar radiation, whereas in indirect solar drying the sun's energy is harnessed by collectors used to heat the air that will be used for drying food. For centuries, fruit, vegetables, meat and fish were dried by direct sunlight, in open air exposure [4].

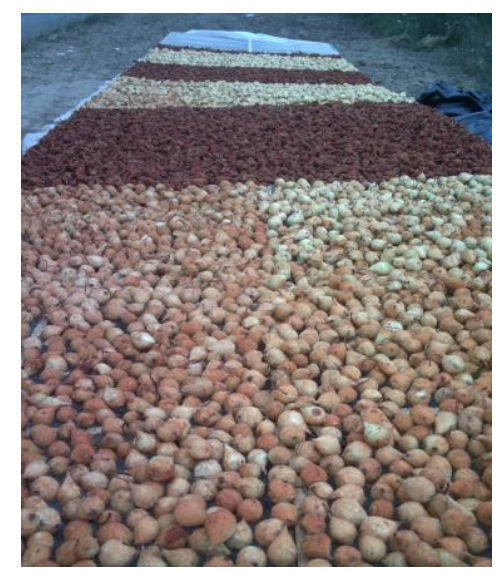

Figure 1. Solar Drying of pears.

\section{B. Hot Air Convective Drying}

The convective drying of porous media, including foods, has a pivotal role in several industrial applications. Owing to its high availability and moisture saturation capacity, the air is undoubtedly the most used drying fluid [10].

The methods in which hot air is used for drying foods are very versatile and have a considerable importance. These include drying in chambers with trays (Fig. 2) or in tunnels equipped with conveyor belts (Fig. 3), in rotating drum driers or even in fluidized bed driers.

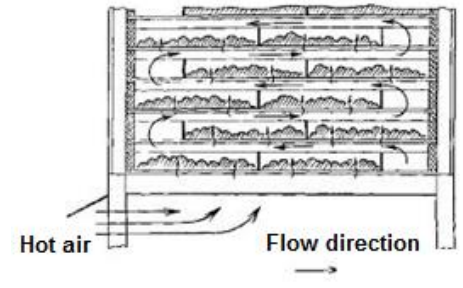

Figure 2. Convective drying in chambers with trays.

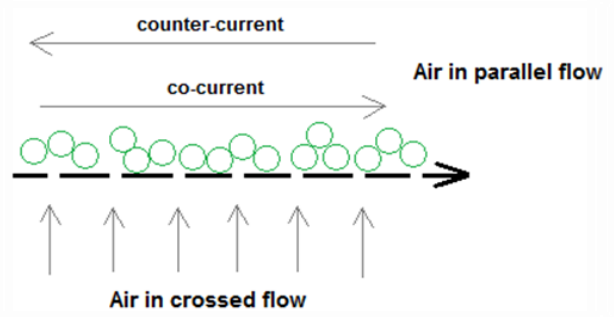

Figure 3. Types of flow in tunnels for convective drying.

The hot air drying is still extensively employed as a food preservation method. However, it adversely affects the final quality of the product. Convective drying is considered as a highly destructive operation, due to shrinkage, discoloration and loss of nutrients, which are particularly problematic for thermally sensitive materials such as fruits and vegetables. Moreover, hot air drying is usually undesirable long-lasting and energy consuming process of food preservation. One of the recommended ways to minimize these harmful impacts of convective drying is application of hybrid methods, where the energy is provided alternatively by combination of different energy sources, like convection with ultrasound or microwave radiation [11].

\section{Spray Drying}

Spray drying is a widely used technique to convert a liquid state into a powder form. It is used for solutions or slurries that go through an atomizer or spray in order to divide the material into droplets $(10-200 \mu \mathrm{m})$. The quality of spray-dried microcapsules is quite dependent on processing parameters of the spray dryer and properties or composition of the feed solution [12].

Given the reduced dimensions, the drying time is short (1-20 s) so damages are limited and it can be used to treat heat-sensitive materials. The atomizer is essential because it determines the size of the droplets and conditions the efficiency of the process. Furthermore spray drying is the most common microencapsulation process and has proven to be an effective technology in protecting bioactive compounds and probiotics. It consists in converting water suspensions into powdered microparticles, which are composed of a wall material (shell) and a core (encapsulated material) [13], [14].

\section{Lyophilization}

In lyophilization, also called freeze-drying or freezedehydration, the water is first frozen and then sublimated, under special conditions of pressure and temperature. 
Lyophilization is slower and with higher costs, because it involves freezing, the production of vacuum and the equipment is itself expensive [15].

Lyophilization is used in industry for the dehydration of foods with high value and delicate aroma and (for example: mushrooms, herbs and spices, fruit juices, meats, seafood or complete diets for military use or sport expeditions), as well as for the preservation of microbial cultures used in the food industry. Lyophilization is usually preferred to convert heat sensitive materials into powder form because is better at preserving their native conformations. However, long processing times, low production throughput, batch mode of production and possible chill injury associated with freezing are considerable disadvantages of this process [16].

\section{E. Infrared Drying}

In infrared drying, the solid food is exposed to a source of infrared heating increasing the temperature of its surface. Because most of the solids have a low thermal conductivity, the rate of heat conduction to the interior is very slow. Hence, the application of infrared radiation primarily intends the surface treatment of foods.

Infrared heating offers many advantages over conventional drying under similar conditions. Comparative studies for infrared drying versus other techniques have proven these benefits. Infrared radiation energy is transferred from the heating element to the product, heating the material more rapidly and uniformly without heating the surrounding air, and hence the energy is used in a more efficient way. The irradiated surface evaporates much more water and drying time is shortened by up to half. Infrared radiation has been applied in conjunction with several drying processes because of these advantages. Combined with hot air pre-drying, infrared heating can save $20 \%$ of drying time compared with the infrared drying alone [5].

\section{F. Microwave Drying}

This method provides a high heating rate and does not originate alterations on the surface of the food and hence no crust is formed. The industrial microwave treatment is limited due to its high cost and to the need to synchronize the generator for different foods. Thus, it is used industrially for low moisture foods, or as a final stage of the dehydration process. Microwave drying is an efficient method for postharvest processing of agricultural products due to time efficiency, low energy consumption and high product quality, which are major factors to be considered by the industry. With the development of new technologies, more parameters can be monitored and controlled during the drying process, such as temperature, weight, power or odour [17].

Compared to convective drying, microwave drying can be advantageous due to its volumetric heating and reduced processing time. On the other hand, it may cause overheating of particles and undesired degradation of bioactive compounds, but the use of microwaves under vacuum may significantly prevent from quality degradation of heat-sensitive materials. But it is important to notice that the use of microwaves under reduced pressure increases the drying costs, which could however be minimized by combining the two drying processes: microwave vacuum with convection [18].

\section{G. Radiofrequency Drying}

The use of radiofrequency energy for dielectric heating of food materials is an important application area, which has been studied as a possible method for drying agricultural products. The radiofrequency heating addresses directly the product, so that its interior is heated faster than its surface. The water is released without overheating or dehydration of the surface. Therefore, it can be used as a complement to other drying processes, and allows to reach very low humidity levels, of the order of 1 to $2 \%$, with minimal impact on quality. This novel drying method provides shorter time, higher energy efficiency and better product quality as compared to conventional hot air heating [19], [20].

\section{H. Osmotic Dehydration}

Osmotic dehydration is based on the principle that when cellular materials are immersed in a hypertonic aqueous solution, a driving force for water removal sets up because of the higher osmotic pressure of the hypertonic solution. It is generally used for partial removal of water from fruits or vegetables which are immersed in a sugar or salt solution (which has an osmotic pressure higher than the food). The food loses water to the solution but in many cases its final moisture content is not stable $(0.90 \leqslant \mathrm{aw} \leqslant 0.95)$ [21], [22].

The water loss rate is initially high, but after $1-2 \mathrm{~h}$ is very much reduced so that it can take days until it reaches equilibrium. Typically it requires $4-6 \mathrm{~h}$ to reduce the food to $50 \%$ of its fresh weight, and that is why it is used industrially as a pretreatment for other operations. So, it is necessary to complement the process using other preservation techniques, such as: microwave assisted air drying, ultrasound assisted osmotic dehydration and air drying, osmotic dehydration with moderate electric field and vacuum air drying, blanching and vacuum pulse, ohmic heating and vacuum impregnation, among others [23].

For fruits the hypertonic solution are used sugar solutions (40-70\%), being the most commonly used sugar sucrose, but fructose, glucose or mixtures of glucose / fructose and glucose / polysaccharides are also used. For vegetables are used salt solutions (5-20\%), normally sodium chloride [21].

\section{Combined Processes}

There are many conventional drying methods used in post-harvest technology including solar drying, osmotic dehydration, vacuum drying, hot-air drying, fluidized bed drying, and freeze drying. However, most of these drying techniques involve longer drying time and high amount of energy, resulting in poor quality of the dried products. It has been suggested a new way of improving the existing conventional drying processes based on self-heat recuperation technology. However this method, which focuses mainly on increasing the energy efficiency of the drying process, is complex and expensive to adapt. 
In recent studies, there have been significant developments in using novel techniques, like microwave, radio frequency, infrared, pulse electric field, ultraviolet, ultrasound, ohmic, supercritical, and heat pump heating, in the drying of agricultural crops in terms of pretreatment, techniques and equipment design that allow increasing process efficiency and enhance the quality of the final dried products [24].

Some typical combined drying processes include: convection \& microwaves, convection \& osmotic dehydration, convection $\&$ infrared radiation, convection $\&$ ultraviolet radiation, convection \& vacuum, convection \& ultrasound, spray drying \& lyophilization, lyophilization \& ultrasound, lyophilization \& infrared radiation, among many other possible combinations.

\section{EXAMPLES OF DRIED FOODS}

\section{A. Fruits}

Many fruits have been for long dried in the sun, including grapes, figs, dates, pears, peaches and apricots (Fig. 4). Nevertheless, the hot air for drying is also amply applied to fruits such as apple slices, apricot halves, pineapple slices or pears in halves or quarters [25].
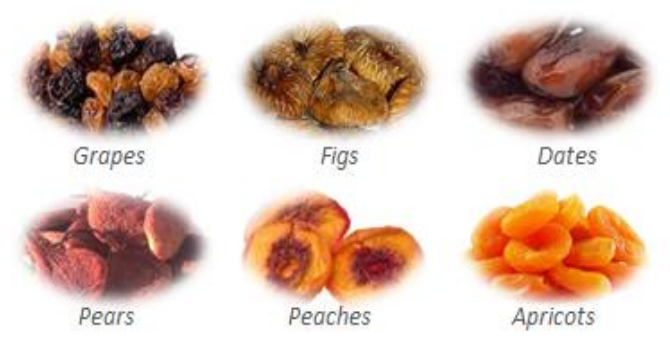

Figure 4. Examples of fruits dried in the sun.

Other drying methods like vacuum (Fig. 5) drying or combined methods can be used to dry fruit, such as kiwi, mango and banana [25].
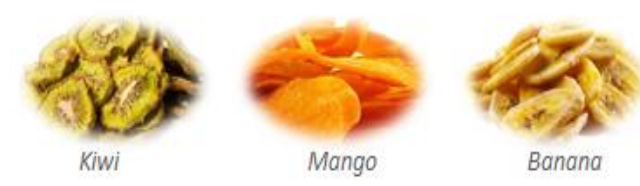

Figure 5. Examples of fruits dried in vacuum.

The osmotic dehydration is applied to orange, pineapple, kiwi, apple, cherry, papaya, coconut, strawberry, among many others (Fig. 6) [25].

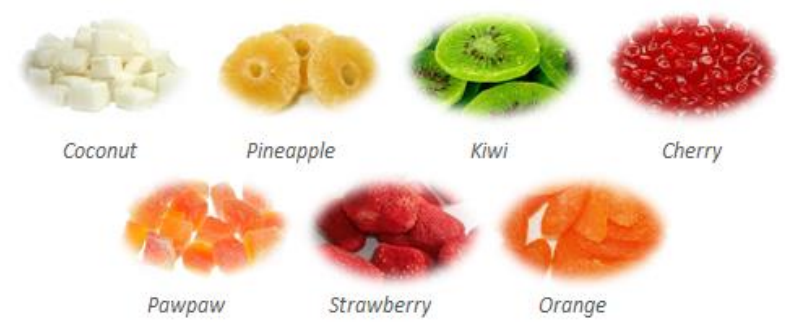

Figure 6. Examples of fruits processed by osmotic dehydration.
In general fruits are not blanched but are sulphited by exposure to vapours resulting from the burning of sulphur, to control minimize browning reactions [26].

Fruit purees can be drum dried to obtain powders or flakes, like in the case of banana, apricot, mango and peach. Some of these products are hygroscopic and sticky, so it is beneficial to add glucose syrup to facilitate removal of the product from the drum and its subsequent handling. For the drying of fruit juices can be used atomization or spray drying (Fig. 7) [25].

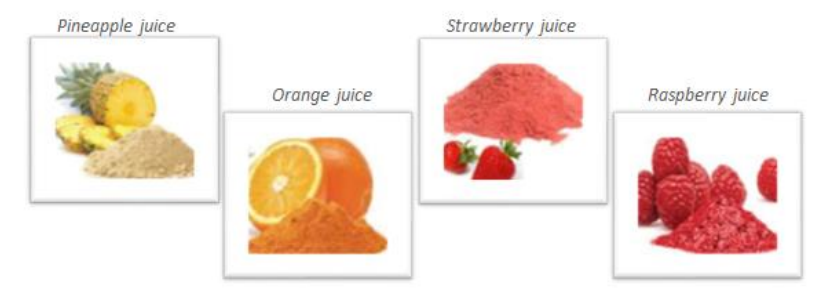

Figure 7. Examples of fruit juices processed by spray drying.

\section{B. Horticultural Products}

Many vegetables can be found in the dried form, such as the tomatoes that are dried in the sun in some countries bordering the Mediterranean. Most vegetables are blanched and/or sulphited before drying. Many different types of dryers are used for drying vegetables such as trays, tunnels or fluidized beds, which use hot air in temperatures normally ranging from 50 to $110^{\circ} \mathrm{C}$ [26].

Among the dried vegetables stand the green beans, peppers, cabbage, carrots, celery, spinach and broccoli (Fig. 8). Some vegetables such as garlic, mushrooms, peas and onions are not sulphited to preserve their delicate taste and aroma, that otherwise would be much affected [25].

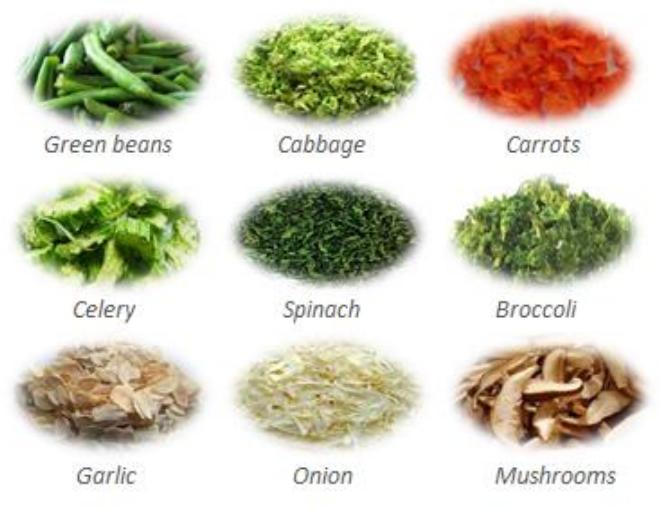

Figure 8. Examples of dried vegetables.

\section{Herbs and Spices}

Herbs and spices can be dried in vacuum dryers to produce products with better organoleptic qualities than those produced by hot air drying. This is why the aromatic herbs for culinary uses are dried in vacuum, so as to preserve their volatile compounds responsible for the aroma and flavour. Some herbs like parsley or thyme can be dried without bleaching or sulphiting. The plants dried for infusions are also dried in vacuum to preserve 
their bioactive compounds responsible for their beneficial health effects [26].

\section{Dairy Products}

The use of drying to preserve milk for applications in baby food dates from 1902, being the milk powders divided into whole milk and skimmed milk powders. The whole raw milk is centrifuged to produce skimmed milk with $0.05 \%$ fat, which is then heat-treated, with an intensity that determines whether the powder produced is classified as low-heat, medium heat or high heat. The more intense the thermal treatment, the lower the amount of soluble serum proteins (albumin and globulin) remaining in the powder. The low-heat powder is used in recombined dairy products, such as cheese and baby food; the medium-heat powder is used in the production of concentrated recombined dairy products; and the highheat powder is mainly used in the bakery and chocolate industries. The milk is then concentrated to a total solids content in the range $40-55 \%$ using a multiple effect evaporator. The skimmed milk is mainly produced by spray drying [26], [27].

\section{E. Fish}

Traditional methods of extending the shelf life of fish include salting and smoking. The salting corresponds to a osmotic dehydration in which the salt is introduced into fish to reduce the water activity (Fig. 9).

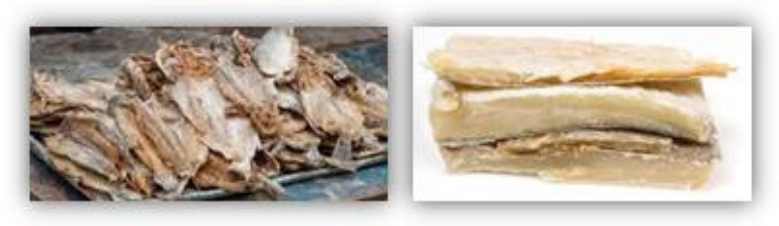

Figure 9. Salted fish

The smoking involves exposure of fish to wood smoke (Fig. 10), which can be done at a relatively low temperature, $\sim 30{ }^{\circ} \mathrm{C}$, in which case the process is known as cold smoking. During smoking there may occur a loss of moisture of $10-11 \%$ and the cold smoked fish products can be refrigerated, which gives them a shelf life of about 7 days. The hot smoking is carried out at temperatures up to $120{ }^{\circ} \mathrm{C}$, and these products may have sufficiently low water activity which allows them to be stable without refrigeration. Lyophilized fish products are also available, but due to the high cost of this type of processing, lyophilization is used only for relatively expensive products such as shrimps [25].

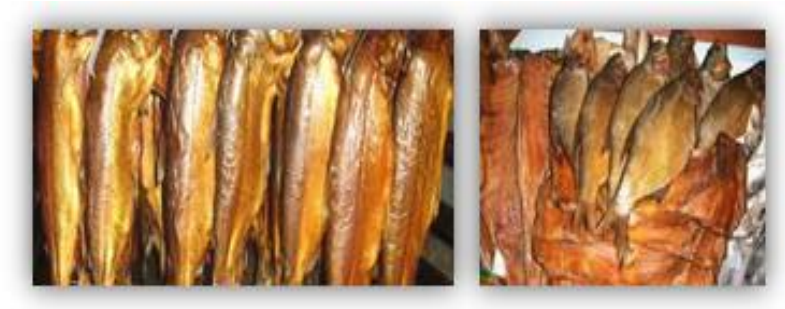

Figure 10. Smoked fish.

\section{F. $\quad$ Meat}

Cooked minced meat (chicken, beef, lamb and pork) may be dried by hot air in tray dryers, conveyors, fluidized beds or rotary driers until a moisture content of 4-6\% (wet basis). When dried, chicken meat is the most stable while pork is the least. The main cause of deterioration of such products is the oxidation of fat that leads to rancidity. The cooked minced meat can also be dried under vacuum, allowing obtaining better products, but also at a higher cost. Both raw and cooked meet in the form of steaks, slices, cubes or minced can be lyophilized to a moisture content of $1.5-3.0 \%$ (wet basis), at an even higher cost [25].

\section{EFFECTS OF DRYING ON FOOD PROPERTIES}

\section{A. Microstructure and Texture}

Factors that affect the structure of dehydrated fruits and vegetables are the type of pre-treatment applied to the materials (blanching, peeling, cutting, ...) together with the intensity with which it is applied [25].

Blanching is a previous operation of great importance in drying materials of plant origin, because it neutralizes the polyphenoloxidase (PPO). Even when it is well done, it causes textural changes owing to starch gelatinization, cellulose crystallization and internal tensions originated by localized variations in moisture. These originate ruptures and compressions which cause permanent distortions in the cells, providing them with a roughed aspect. When rehydrated these foods absorb water more slowly and fail to gain back the firm texture of the original raw material [25].

The dehydration temperature and rate have great influence on the texture of the food and, in general, faster processes and higher temperatures cause greater changes. The water that migrates to the surface carries solutes from the food, originating tensions in the structure, variable according to the type of food, its composition and the processing parameters. The drying may cause some changes in mechanical properties, structure, volume, porosity and density of the foods [18].

The high temperature causes profound physical and chemical alterations on the surface of the foods, thus leading to the formation of a hard impenetrable surface layer, which keeps the foods dried at the surface but moist inside. The structural changes during drying influence the texture of the final product, according to the rate of water elimination. If shrinkage occurs, like in the air dried foods, a very dense structure is formed and the dried product is harder (Fig. 11). On the contrary, if no shrinkage occurs, like in the case of lyophilized foods, a highly porous structure is formed and the product has a smoother texture (Fig. 12) [25].
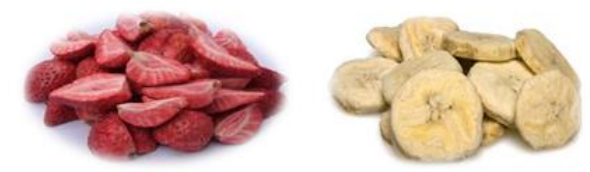

Figure 11. Highly porous freeze dried fruits (strawberries and bananas). 


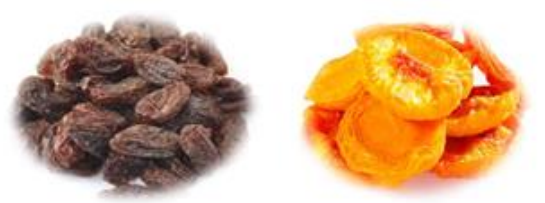

Figure 12. Dense air dried fruits (raisins and peaches).

\section{B. Colour}

Enzymatic browning is one of the important browning reactions in fruits and vegetables during thermal processing and that includes drying (Fig. 13).
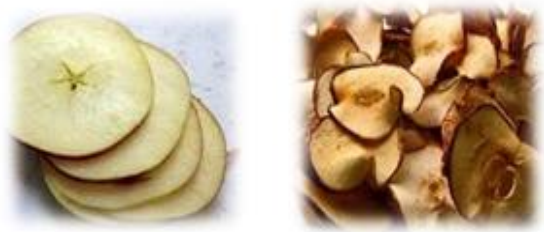

Figure 13. Darkening of apple slices during drying due to polyphenoloxidase activity.

The enzyme PPO is widely distributed among plant materials and may cause undesirable colour and flavour changes during post-harvest processing, due to enzymatic browning, when in the presence of oxygen. Therefore, enzyme deactivation is usually an essential treatment prior to any preservation process such as drying, and which largely determines the product quality [28].

Dehydration alters the surface characteristics of the food, and thus the colour and reflectance. Chemical changes in pigments such as carotene and chlorophyll are produced by heat and oxidation that occur during drying (Fig. 14). In general, the longer the process and the higher the temperature, the greater are the losses in these pigments [25].
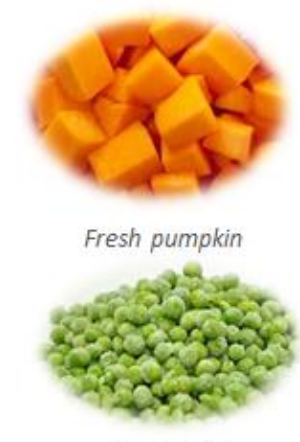

Fresh peas
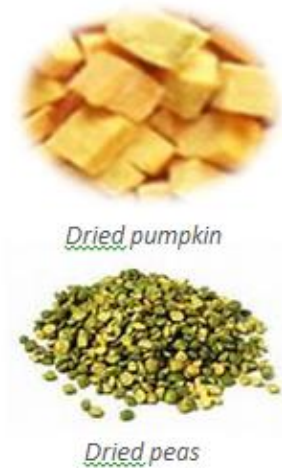

Figure 14. Discoloration of pigments with drying (carotenoids and chlorophyll).

The optimum $\mathrm{pH}$ for the activity of the PPO is between 6 and 7, so that for $\mathrm{pH} \leq 4$ it becomes inactive. Hence it is recommended the addition of citric or ascorbic acid to lower the $\mathrm{pH}$. On the other hand, sulphur compounds (exposure to the vapours resulting from the burning of sulphur or dipping in aqueous solutions of bisulphite or metabisulphite) have also been used to avoid the browning reactions. However, in some cases we must pay attention to the concentrations used to avoid unpleasant flavours [29]. Finally, the activity of PPO is also inhibited in the absence of the oxygen, for which the reduction of the oxygen concentration of the drying atmosphere is also beneficial, such as when the drying is done under vacuum [25].

Among the non-enzymatic browning reactions stand the Maillard and the caramelization reactions. The Maillard reaction involves the amino acids and the reducing sugars resulting in the formation of melanoidins, with consequent loss of nutritive value. These reactions start at $70{ }^{\circ} \mathrm{C}$ and their rate is dependent on the type of sugars present in the food. Also the foods with water activity in the range $0.5-0.8$ are more susceptible to nonenzymatic browning. Caramelization reactions happen with sugars for temperatures higher than $120{ }^{\circ} \mathrm{C}$ originating dark products named caramels [29].

\section{Chemical Composition and Nutritional Value}

Drying can significantly alter the food chemical composition and nutrients, with an extension variable according to the type of food, drying method, intensity of treatment and operating conditions (Fig. 15). Changes in nutritional value of dried foods may be due to preparation systems (pre-treatments), drying conditions (particularly temperature) or storage conditions (after drying). Some measures that can be taken to reduce nutrient losses include: minimize drying time, use lower temperatures, and during storage maintain low levels of moisture and oxygen concentration [25].

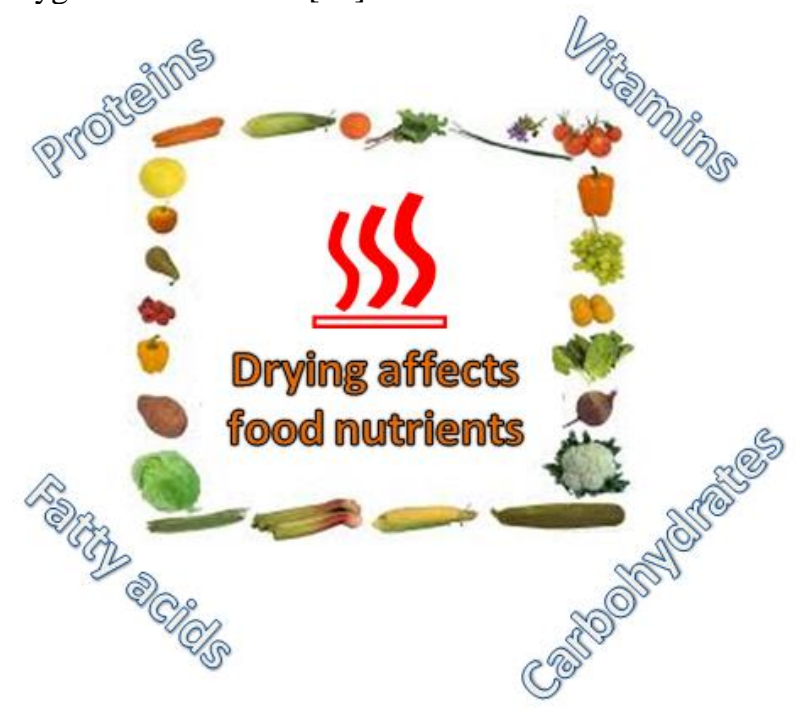

Figure 15. Effect of drying on food nutrients.

The water solubility of vitamins is variable. As drying proceeds, some vitamins (ex. riboflavin) reach oversaturation and precipitate and therefore lower losses occur. Others (ex. vitamin C) are maintained dissolved until the moisture content in the food is very low, and react with the solutes at a greater rate as the process advances. The vitamin $\mathrm{C}$ is particularly affected by heat and oxidation and also the thiamine is relatively sensitive to heat. The liposoluble vitamins are more stable to heat and oxidation (with losses $<10 \%$ ), but may react with peroxides resulting from lipid oxidation [25], [29]. 
The liposoluble nutrients (ex. Essential fatty acids and vitamins A, D, E e K) are present mostly in the dry matter of the food and that why the losses during drying are not so important.

The dietary minerals (copper and iron) act as catalysers in oxidation reactions of unsaturated lipids and are dissolved in the aqueous phase of the food. Hence, during drying water is eliminated and their reactivity diminishes, thus giving a better preservation of the nutritional value.

The biological value and digestibility of proteins in most foods does not change with drying. However, it may occur denaturation in some foods and under some operating conditions [25], [29].

\section{Aroma}

Heat originates losses in volatile components from the food, according to the processing temperature, the vapour pressure of the volatile substances, their solubility in water vapour and the concentration of solids in the food.

Some methods for protecting the flavour of dehydrated food include: working at low temperature and/or use vacuum, promote the activation of natural enzymes in the foods or add external enzymes which originate aromatic substances from the natural aroma precursors, use compounds fixators of aroma, and do the recovery of the volatile compounds to add the again to the product [25].

\section{CONCLUSION}

The drying operation is a very ancient practice for food preservation, but instead of being abandoned presently it continues very important industrial process of treatment for diversified food products. Much innovation and technological advancements have led to better drying processes, more efficient in energetic terms and allowing a better preservation of the organoleptic and nutritional qualities. The applicability of the process to a wide range of foods, with diverse characteristics render this operation a prominent position in the processing food industries.

\section{ACKNOWLEDGMENT}

This participation is financed by national funds through FCT - Fundação para a Ciência e Tecnologia, I.P., under the project UID/Multi/04016/2016. Furthermore we would like to thank the Polytechnic Institute of Viseu and CI\&DETS for their support.

\section{REFERENCES}

[1] M. M. Muliterno, D. Rodrigues, F. S. de Lima, E. I. Ida, and L. E. Kurozawa, "Conversion/degradation of isoflavones and color alterations during the drying of okara," LWT - Food Science and Technology, vol. 75, pp. 512-519, Jan. 2017.

[2] A. C. Cruz, R. P. F. Guiné, and J. C. Gonçalves, "Drying kinetics and product quality for convective drying of apples (cvs. Golden Delicious and Granny Smith)," International Journal of Fruit Science, vol. 15, no. 1, pp. 54-78, Jan. 2015.

[3] R. P. F. Guiné, P. Lopes, M. J. Barroca, and D. M. S. Ferreira, "Effect of ripening stage on the solar drying kinetics and properties of S. Bartolomeu pears (Pirus Communis L.)," International Journal of Academic Research, vol. 1, no. 1, pp. 4652, 2008.

[4] R. Guiné, "Analysis of the drying kinetics of S. Bartolomeu pears for different drying systems," EJournal of Environmental,
Agricultural and Food Chemistry, vol. 9, no. 11, pp. 1772-1783, 2010 .

[5] N. Adak, N. Heybeli, and C. Ertekin, "Infrared drying of strawberry," Food Chemistry, vol. 219, pp. 109-116, Mar. 2017.

[6] G. P. Sharma, R. C. Verma, and P. B. Pathare, "Thin-layer infrared radiation drying of onion slices," Journal of Food Engineering, vol. 67, no. 3, pp. 361-366, Apr. 2005.

[7] G. D. da Silva, Z. M. P. Barros, R. A. B. de Medeiros, C. B. O. de Carvalho, S. C. Rupert Brandão, and P. M. Azoubel, "Pretreatments for melon drying implementing ultrasound and vacuum," LWT - Food Science and Technology, vol. 74, pp. 114119, Dec. 2016.

[8] A. Ziaforoughi and J. A. Esfahani, "A salient reduction of energy consumption and drying time in a novel PV-solar collectorassisted intermittent infrared dryer," Solar Energy, vol. 136, pp. 428-436, Oct. 2016.

[9] Y. Qiu, M. Li, R. H. E. Hassanien, Y. Wang, X. Luo, and Q. Yu, "Performance and operation mode analysis of a heat recovery and thermal storage solar-assisted heat pump drying system," Solar Energy, vol. 137, pp. 225-235, Nov. 2016.

[10] T. Dobre, O. C. Pârvulescu, A. Stoica-Guzun, M. Stroescu, I. Jipa, and A. A. A. Al Janabi, "Heat and mass transfer in fixed bed drying of non-deformable porous particles," International Journal of Heat and Mass Transfer, vol. 103, pp. 478-485, Dec. 2016.

[11] J. Szadzińska, J. Łechtańska, S. J. Kowalski, and M. Stasiak, "The effect of high power airborne ultrasound and microwaves on convective drying effectiveness and quality of green pepper," Ultrasonics Sonochemistry, vol. 34, pp. 531-539, Jan. 2017.

[12] L. Hu, et al., "Microencapsulation of brucea javanica oil: Characterization, stability and optimization of spray drying conditions," Journal of Drug Delivery Science and Technology, vol. 36, pp. 46-54, Dec. 2016.

[13] L. Medina-Torres et al., "Microencapsulation by spray drying of laurel infusions (Litsea glaucescens) with maltodextrin," Industrial Crops and Products, vol. 90, pp. 1-8, Nov. 2016.

[14] S. Huang, et al., "Double use of concentrated sweet whey for growth and spray drying of probiotics: Towards maximal viability in pilot scale spray dryer," Journal of Food Engineering, vol. 196, pp. 11-17, Mar. 2017.

[15] B. Wang, Y. P. Timilsena, E. Blanch, and B. Adhikari, "Characteristics of bovine lactoferrin powders produced through spray and freeze drying processes," International Journal of Biological Macromolecules, vol. 95, 2017.

[16] M. Haque and B. Adhikari, "Drying and denaturation of proteins in spray drying process," in Handbook of Industrial Drying, Fourth Edition, CRC Press, 2014, pp. 971-983.

[17] H. Pu, Z. Li, J. Hui, and G. S. V. Raghavan, "Effect of relative humidity on microwave drying of carrot," Journal of Food Engineering, vol. 190, pp. 167-175, Dec. 2016.

[18] M. Zielinska and A. Michalska, "Microwave-assisted drying of blueberry (Vaccinium corymbosum L.) fruits: Drying kinetics, polyphenols, anthocyanins, antioxidant capacity, colour and texture," Food Chemistry, vol. 212, pp. 671-680, Dec. 2016.

[19] X. Zhu, W. Guo, X. Wu, and S. Wang, "Dielectric properties of chestnut flour relevant to drying with radio-frequency and microwave energy," Journal of Food Engineering, vol. 113, no. 1, pp. 143-150, Nov. 2012.

[20] M. Michael, R. K. Phebus, H. Thippareddi, J. Subbiah, S. L. Birla, and K. A. Schmidt, "Validation of radio-frequency dielectric heating system for destruction of Cronobacter sakazakii and Salmonella species in nonfat dry milk," Journal of Dairy Science, vol. 97, no. 12, pp. 7316-7324, Dec. 2014.

[21] N. Barman and L. S. Badwaik, "Effect of ultrasound and centrifugal force on carambola (Averrhoa carambola L.) slices during osmotic dehydration," Ultrasonics Sonochemistry, vol. 34, pp. 37-44, Jan. 2017.

[22] I. Eren and F. Kaymak-Ertekin, "Optimization of osmotic dehydration of potato using response surface methodology," Journal of Food Engineering, vol. 79, no. 1, pp. 344-352, Mar. 2007.

[23] A. S. da Costa Ribeiro, E. Aguiar-Oliveira, and R. R. Maldonado, "Optimization of osmotic dehydration of pear followed by conventional drying and their sensory quality," LWT - Food Science and Technology, vol. 72, pp. 407-415, Oct. 2016.

[24] D. I. Onwude, N. Hashim, and G. Chen, "Recent advances of novel thermal combined hot air drying of agricultural crops," 
Trends in Food Science \& Technology, vol. 57, Part A, pp. 132145, Nov. 2016

[25] R. P. F. Guiné, Food Drying and Dehydration: Technology and Effect on Food Properties, Germany: LAP Lambert Academic Publishing $\mathrm{GmbH} \& \mathrm{Co}, 2015$.

[26] J. G. Brennan and A. S. Grandison, Food Processing Handbook, 2nd ed., New York: Wiley, 2011.

[27] P. M. Kelly, "Milk Powders," in Hui, Y.H. Food drying. Science and Technology, Pennsylvania, USA: DEStech Publications, Inc, 2008, pp. 693-719.

[28] J. Wang, et al., "Effect of high-humidity hot air impingement blanching (HHAIB) on drying and quality of red pepper (Capsicum annuum L.)," Food Chemistry, vol. 220, pp. 145-152, Apr. 2017.

[29] S. M. C. Celestino, Princípios de Secagem de Alimentos, Planaltina, Brazil: Embrapa, 2010.

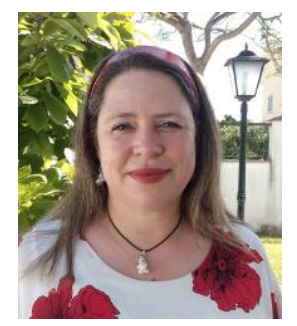

Raquel P. F. Guiné has a degree in Chemical Engineering (1991), a MsC in Engineering Science (1997) and a PhD in Chemical Engineering (2005), all at the Faculty of Science and Technology of the University of Coimbra (Portugal). She has a Teaching Habilitation in Food Science (2015) from the University of Algarve (Portugal). She has a Certificate of Proficiency in English (CPE, 1986) by the University of Cambridge (United Kingdom). Her major fields of study include food engineering and food processing.

She has been a University Teacher since 1994, being presently a Coordinating Professor with Habilitation at the Food Industry
Department in Polytechnic Institute of Viseu - IPV (Portugal). Has been President of the Scientific Board; President of the Assembly of Representatives; Director of Licence Course, Director of MsC Course, and presently is Head of Department all at ESAV, IPV (Portugal). Is author of 14 books, 39 chapters, 149 research papers and 176 conference proceedings. Has authored 110 oral communications and 94 posters presented at scientific conferences. Selected published books: Vitamin C. Dietary Sources, Technology, Daily Requirements and Symptoms of Deficiency (New York, USA: Nova Science Publishers, 2013); Engineering Aspects of Cereal and Cereal-Based Products (Boca Raton, USA: CRC Press, 2013); Handbook of Fruit and Vegetable Flavors (New York, USA: John Wiley \& Sons, 2010). Her research interests include areas such as food engineering, food processing, food properties, food chemistry and nutrition.

Prof. Guiné is a member of the Portuguese Chemical Society (SPQ) and Asia-Pacific Chemical, Biological \& Environmental Engineering Society (CBEES). Awards: 2011 - Research Project distinguished (Project lead by her); 2011 - Certificate of Excellence of paper published in Food and Bioproducts Processing in 2010; 2013 - First Prize in the National Contest sponsored by the CAP relative to a new food developed; 2015 - Certificate of Excelence for oral comunication presented at 2nd International Conference on Food and Nutrition Technology (ICFNT 2015), Jeju Island, Republic of Korea; 2015 - Bes Scientific Paper CI\&DETS Published in 2014, in the Research Group in Food, Agrarian and Veterinary Sciences; 2016 - Certificate of Best Oral Presentation for communication presented at the 2nd International Conference on Food and Agricultural Engineering (ICFAE 2016), Copenhagen, Denmark; 2016 - Third Prize in the Regional Contest Poliempreende relative to a new entrepreneurship idea; 2016 - Best Scientific Paper CI\&DETS Published in 2015, in the Research Group in Food, Agrarian and Veterinary Sciences. (URL: www.raquelguine.pt) 